\title{
Rabaska
}

Revue d'ethnologie de l'Amérique française

\section{Loyola, AnNABel. Le Dernier Souffle. Au coeur de l'Hôtel-Dieu de Montréal. Saint-Calixte (Québec), Amazone Film, 2017, DVD, 72 min.}

\section{Diane Joly}

Volume 16, 2018

URI : https://id.erudit.org/iderudit/1051361ar

DOI : https://doi.org/10.7202/1051361ar

Aller au sommaire du numéro

Éditeur(s)

Société québécoise d'ethnologie

ISSN

1703-7433 (imprimé)

1916-7350 (numérique)

Découvrir la revue

Citer ce compte rendu

Joly, D. (2018). Compte rendu de [Loyola, AnNabel. Le Dernier Souffle. Au coeur de l'Hôtel-Dieu de Montréal. Saint-Calixte (Québec), Amazone Film, 2017, DVD, 72 min.] Rabaska, 16, 306-307. https://doi.org/10.7202/1051361ar d'utilisation que vous pouvez consulter en ligne.

https://apropos.erudit.org/fr/usagers/politique-dutilisation/ 


\section{Films}

Loyola, Annabel. Le Dernier Souffle. Au cœur de l'Hôtel-Dieu de Montréal. Saint-Calixte (Québec), Amazone Film, 2017, DVD, 72 min.

Le Dernier Souffle rend hommage à une institution vieille de 375 ans appelée à disparaître dans les prochaines années. C'est aussi un hommage aux gens qui la font vivre - employés, patients et familles, bénévoles, et ceux qui y transitent pour un travail ponctuel. Ce titre rappelle aussi que l'établissement s'est spécialisé dans les soins cardiaques et la fibrose kystique, deux maladies où le souffle vient à manquer, et enfin aux patients qui y décèdent. C'est également une révérence aux sœurs hospitalières de Saint-Joseph qui y œuvrent depuis les débuts dans le sillage de Jeanne Mance, cofondatrice de Montréal.

Comment donner du cœur à l'Hôtel-Dieu ? D'entrée de jeu, une sœur hospitalière explique que ce questionnement est l'héritage laissé par Jeanne Mance. Et c'est ce que veut montrer, avec beaucoup de sensibilité, Annabel Loyola, qui a offert un documentaire sur la fondatrice en 2010 (Rabaska, vol. 14, 2016).

Le film se déroule sur une année entre les murs de l'institution et les terrains des sœurs hospitalières qui abritent un grand jardin potager, un verger et une ruche, dont les soins, selon les saisons, rythment le passage du temps.

La trame narrative repose sur des entrevues avec des gens qui rendent vivant ce lieu - du médecin à l'administrateur, du préposé au personnel de l'entretien, des bénévoles aux bénéficiaires et leurs familles. Tout autant de points de vue sur la place de l'Hôtel-Dieu à Montréal et dans leur vie. Ainsi, pour certains, c'est un lieu rempli d'histoire où l'on comprend mal pourquoi le nom Hôtel-Dieu n'a pas été intégré dans le toponyme des nouveaux centres hospitaliers. Pour d'autres c'est une grande famille, un lieu de sérénité.

En premier, chacune des personnes interrogées met en lumière la synergie de ses responsabilités au bon fonctionnement du lieu - que ce soit le peintre qui met de la beauté dans la place, le technicien en bâtiment qui produit des archives utiles pour l'avenir du site et l'administrateur qui s'attarde à la pérennité des lieux. Viennent ensuite les personnes qui travaillent auprès des bénéficiaires, médecins, infirmières, professionnels auxquels s'ajoute l'Association des auxiliaires bénévoles créée par les religieuses trop débordées pour s'occuper du bien-être et de l'apaisement des bénéficiaires. La cinéaste 
présente aussi trois duos qui incarnent bien l'esprit des lieux. Le premier se compose de deux chirurgiens qui opèrent ensemble depuis une trentaine d'années et dont la complicité lumineuse transpire dans les gestes du quotidien médical et dans leurs échanges. Viennent ensuite une musicienne et un massothérapeute, un couple à la ville qui jumelle le réconfort de la musique et du toucher auprès des patients. Enfin, deux techniciens soulignent une amitié joyeuse où les hommes ont vu naître et grandir les enfants de l'un et l'autre.

Au cœur de cette vie débordante, on retrouve les religieuses toujours aussi impliquées auprès des bénéficiaires et de leurs familles. Elles incarnent le quotidien de l'hôpital, et leur sensibilité à la conservation des lieux, notamment la crypte où reposent les restes de 592 religieuses et de Jeanne Mance. En 2016, les religieuses ont décidé de vendre à la Ville la partie du site qui leur appartenait : le couvent, les jardins, le musée, les chapelles et d'autres bâtiments de service. En dépit de cette cession, toutes les sœurs ont décidé de finir leurs jours sur place.

Pour mettre en ordre ce foisonnement de gens et d'interventions, Annabel Loyola les présente au travail. On voit par exemple les chirurgiens dans la salle d'opération, des bénévoles enveloppant des cadeaux de Noël, la musicienne qui bouleverse un ancien professeur de danse avec un tango joué à la harpe. L'une des scènes les plus émouvantes est celle d'un animateur de pastorale qui recueille le « testament intellectuel » d'un patient en fin de vie.

L'information historique est peu présente. La longue durée se révèle par le recours à des photographies d'archives et à quelques événements historiques. On souligne entre autres la fondation de l'Hôtel-Dieu en 1642, l'hommage spontané des Montréalais lors de la translation des restes de Jeanne Mance et des sœurs fondatrices vers le site actuel en 1861 et la création du Centre de recherche de l'Hôtel-Dieu au pavillon Masson où le directeur rappelle que ce sont les sœurs qui ont offert gratuitement l'emplacement au rez-dechaussée pour y créer le centre tandis qu'elles logeaient au deuxième. On imagine facilement combien cette cohabitation intergénérationnelle a pu être profitable tant aux jeunes étudiants en médecine qu'aux religieuses.

Ébranlée par l'annonce de la vente future de l'Hôtel-Dieu, Annabel Loyola s'était donné la mission de révéler l'institution par son patrimoine et ses gens. C'est la grande force de ce documentaire qui met en lumière l'apport crucial de tout un chacun et qui incarne à merveille la règle de Jeanne Mance : comment donner du cœur à l'institution ? L'approche profondément humaine, intimiste même de la cinéaste donne vie à l'Hôtel-Dieu où les gens qui verront sa fermeture définitive demeurent néanmoins optimistes quant à son avenir. C'est à suivre.

Diane Joly

Société québécoise d'ethnologie 